\title{
Tumor do saco vitelínico em mediastino anterior: um relato de caso
}

\author{
Yolk Sac Tumor in anterior mediastinum: a case report \\ Tumor del saco vitelino em mediastino anterior: informe de un caso
}

\begin{abstract}
Bianca Fadul de Oliveira Peixoto ${ }^{1 *}$, Ciro de Castro Botto ${ }^{1}$, Gustavo Assumpção Teixeira ${ }^{1}$, Eduardo Ruas Martins Batista1, Marcelo de Paula Lima ${ }^{1}$, Ana Cláudia Fernandes Azarias
\end{abstract}

\section{RESUMO}

Objetivo: Relatar um caso raro de tumor de células germinativas não seminomatoso do tipo "Yolk Sac Tumor" ou "Saco vitelínico" em mediastino anterior em paciente jovem com desfecho desfavorável. Detalhamento do caso: Homem jovem com apresentação inicial insidiosa de mal-estar e febre em domicílio, com procuras frequentes ao atendimento primário. Com a progressão dos sintomas, foi submetido à radiografia de tórax, sendo evidenciado alargamento de mediastino anterior e optou-se por internação para elucidação diagnóstica. Cursou com piora gradativa dos sintomas e com aumento exponencial do tamanho da massa mediastinal. Realizaram-se duas biópsias, sendo que a segunda demonstrou se tratar de um tumor de células germinativas não seminomatoso do tipo do saco vitelínico. Apresentava alfafetoproteína de 24.563. Evoluiu com necessidade de cuidados intensivos e ventilação mecânica. Recebeu primeira sessão de quimioterapia, porém, foi a óbito com quatro meses de evolução da doença. Considerações finais: Os tumores de mediastino anterior são diversos e não se limitam aos teratomas, timomas e linfomas. Os tumores derivados das células germinativas extragonadais são exemplos que acometem homens jovens e apresentam prognóstico reservado.

Palavras-chave: Neoplasias do mediastino, Neoplasias embrionárias de células germinativas, Tumor do seio endodérmico.

\section{ABSTRACT}

Objective: To report a rare case of a non-seminomatous germ cell tumor of the type "Yolk Sac Tumor" in the anterior mediastinum in a young patient with an unfavorable outcome. Case report: Young man with initial insidious presentation of malaise and fever at home, frequently visiting primary care. Because of the progression of symptoms, he underwent chest X-ray, this exam evidenced widening of the anterior mediastinum and it was opted for hospitalization and diagnostic clarification. It took place with a gradual worsening of symptoms and an exponential and rapid increase in the size of the mediastinal mass. Two biopsies were performed, the second one demonstrated that it was a non-seminomatous germ cell tumor of the yolk sac type. It had 24,563 alpha-fetoprotein. The patient evolved in need of intensive care and mechanical ventilation. He received his first chemotherapy session, but died after four months of the disease. Final considerations: Anterior mediastinal tumors are diverse and are not limited to teratomas, thymomas and lymphomas. Tumors derived from extragonal germ cells are examples that affect young men and have a poor prognosis.

Keywords: Mediastinal neoplasms, Germ cell embryonic neoplasms, Endodermal sinus tumor.

\section{RESUMEN}

Objetivo: Describir el caso clínico de un tumor mediastinal de células germinativas no-seminona tipo "Yolk Sac" in hombre joven. Caso clínico: Paciente masculino, de 29 años, con presentación inicial insidiosa de malestar general y fiebre que motivaron visitas frecuentes a la atención primario. Con la progresión de los síntomas, fue solicitada una radiografía de tórax, que evidenció ensanchamiento del mediastino anterior, optando entonces por hospitalización para investigación etiológica. Los exámenes complementarios revelaron nivel sérico de alfafetoproteína muy aumentado $(24.563 \mathrm{ng} / \mathrm{mL})$. Se realizaron dos biopsias, en la segunda muestra fue confirmado el diagnóstico de tumor de células germinales no-seminoma del tipo "Yolk Sac". El paciente evolucionó con empeoramiento gradual de los síntomas y aumento rápido del tamaño de la masa mediastínica con necesidad de cuidados intensivos y ventilación mecánica. Inició esquema de quimioterapia, pero consiguió realizar apenas una sesión, falleciendo a solo cuatro meses del inicio de los primeros síntomas. Consideraciones finales: Teratomas, timomas y linfomas son los tumores más frecuentes en el mediastino anterior, sin embargo, otros de menor prevalencia, como los germinomas primarios extra-gonadales deben estar incluidos también en el diagnóstico diferencial de estas masas.

Palabras clave: Neoplasias mediastínicas, Neoplasias embrionarias de células germinales, Tumor de seno endodérmico.

${ }^{1}$ Santa Casa de Misericórdia de Franca, Franca - SP. *E-mail: bianca_fadul@hotmail.com 


\section{INTRODUÇÃO}

O mediastino é um espaço compreendido entre os dois pulmões, ele é dividido em três compartimentos (baseado em planos com divisões imaginárias sobrepostos à radiografia em perfil). Esta divisão ajuda a caracterizar anatomicamente doenças e tumores de acordo com a localização e o órgão de origem. $O$ compartimento anterior tem uma forma alongada, triangular de base superior e se estende entre o esterno e o pericárdio. Os tumores do mediastino anterior perfazem cerca de $60 \%$ das massas mediastinais como um todo, e as neoplasias derivadas do tecido tímico são as mais comuns (FERNANDEZ A, 2015; MEDEIROS CR, 2000).

O diagnóstico diferencial dos tumores mediastinais depende, basicamente, da localização do tumor. Quase dois terços das neoplasias de localização mediastinal são benignas. Sendo que, as neoplasias malignas são diagnosticadas, respectivamente, em 59\%, 29\% e 16\% dos tumores do mediastino anterossuperior, médio e posterior (JUDICE FL, et al., 2010).

Tumores mediastinais derivados de células germinativas são raros e cerca de 100 casos são diagnosticados anualmente, aproximadamente, 90\% deles ocorrem em homens. Em adultos e adolescentes, o tumor de células germinativas, o sítio extragonadal mais freqüente é o mediastino $(75 \%$ dos casos) (MEDEIROS CR, 2000).

O Tumor do Saco Vitelínico é um tumor mediastinal de células germinativas infrequente. Há casos esporádicos relatados na literatura. São classificados como não seminomatosos, um grupo heterogêneo de tumores malignos, que geralmente acomete adultos jovens do sexo masculino. Ele se apresenta com crescimento acelerado, aspecto grosseiro e rapidamente infiltrativo, tornando seu prognóstico reservado na grande maioria dos casos. Cursam com importante aumento de alfafetoproteína e, algumas vezes gonadodrofina coriônica humana subunidade beta (B-HCG), levantando a importância da solicitação desses marcadores quando na sua suspeita (MORAN CA, et al., 1997).

Muitas dúvidas já foram sanadas sobre a origem desses tumores, inicialmente acreditava se tratar de disseminação de um tumor gonadal primário. Entretanto, foi evidenciado que tais tumores são decorrentes de células germinativas primitivas, as quais durante a embriogênese migraram fisiologicamente ao longo da crista urogenital para outros pontos anatômicos, dentre eles, o mediastino (MORAN CA e KALHOR N, 2018).

Devido à rápida progressão do tumor do saco vitelínico, seu diagnóstico e tratamento é uma verdadeira corrida. Uma vez que, por serem raros, muitas vezes são negligenciados no raciocínio diagnóstico. Ao lembrarmos das demais possibilidades etiológicas que podem acometer o mediastino anterior, aliado a dados epidemiológicos e clínicos de suspeição, poderemos culminar em uma agilidade na sua abordagem e antecipar sua terapêutica, fato que pode contribuir com a sobrevida dos pacientes, os quais muitos ainda se encontram em idade produtiva de trabalho (NAKHLA SG e SUNDARARAJAN S, 2016).

O objetivo do presente trabalho foi relatar um caso raro em um paciente jovem do sexo masculino que desenvolveu tumor em mediastino anterior de células germinativas não seminomatoso, do tipo de seio endodérmico, conhecido como "Yolk Sac Tumor" ou "Tumor do saco vitelínico", subtipo raro e com prognóstico adverso.

\section{DETALHAMENTO DO CASO}

Paciente do sexo masculino, 29 anos. Previamente sem comorbidades, e com desenvolvimento puberal sem alteração, negava uso de medicações diárias, vícios e drogadição. Em sua família havia relato de carcinoma de reto em duas tias maternas.

Iniciou com quadro de febre aferida em domicílio, com médias de 38-39² $\mathrm{C}$, principalmente em período noturno. Concomitantemente, iniciou com quadro generalizado de fraqueza, sudorese e perda de peso (aproximadamente $10 \mathrm{~kg}$ em 1 mês). Neste intervalo, procurou por atendimento médico, sendo submetido a exames gerais e de imagens. No começo de sua sintomatologia, era avaliado e liberado com medicações sintomáticas. 
Devido a persistência dos sintomas, paciente foi submetido novamente a exame de imagem (Figura 1), sendo evidenciado alargamento do mediastino em radiografia torácica póstero-anterior. Diante de tal achado, foi internado para a área de Clínica Médica para elucidação diagnóstica.

Figura 1 - Rx de tórax PA e PERFIL com alargamento de mediastino anterior.
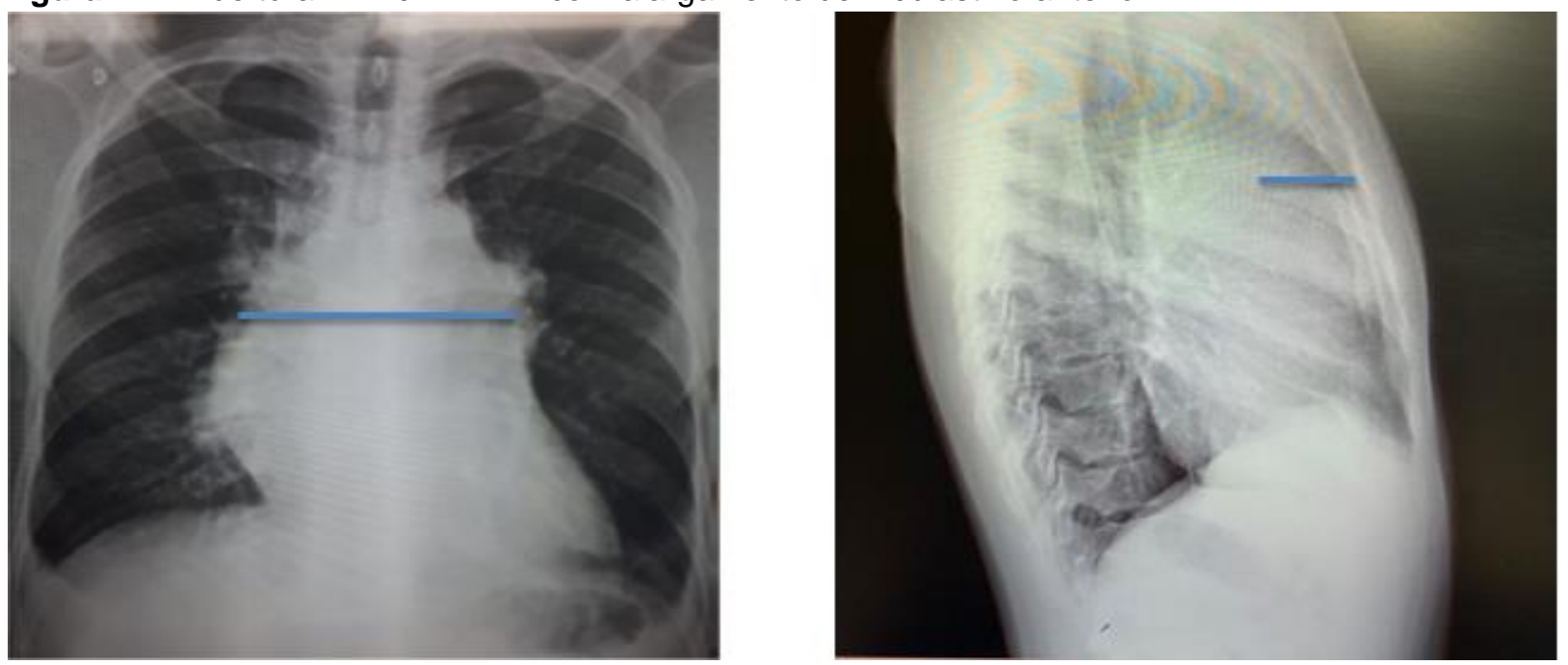

Fonte: Peixoto BFO, et al., 2020.

Durante sua investigação, foram realizados novos exames de imagem. A princípio paciente assintomático, apresentando esporádicos picos febris. Em sua primeira tomografia computadorizada do tórax com contraste, notou-se massa lobulada de tamanho moderado com captação heterogênea de contraste (Figura 2).

Figura 2 - Tomografia computadorizada de tórax com contraste corte coronal demonstrando massa em mediastino anterior com captação de contraste heterogênea, conforme demonstrado pela seta.

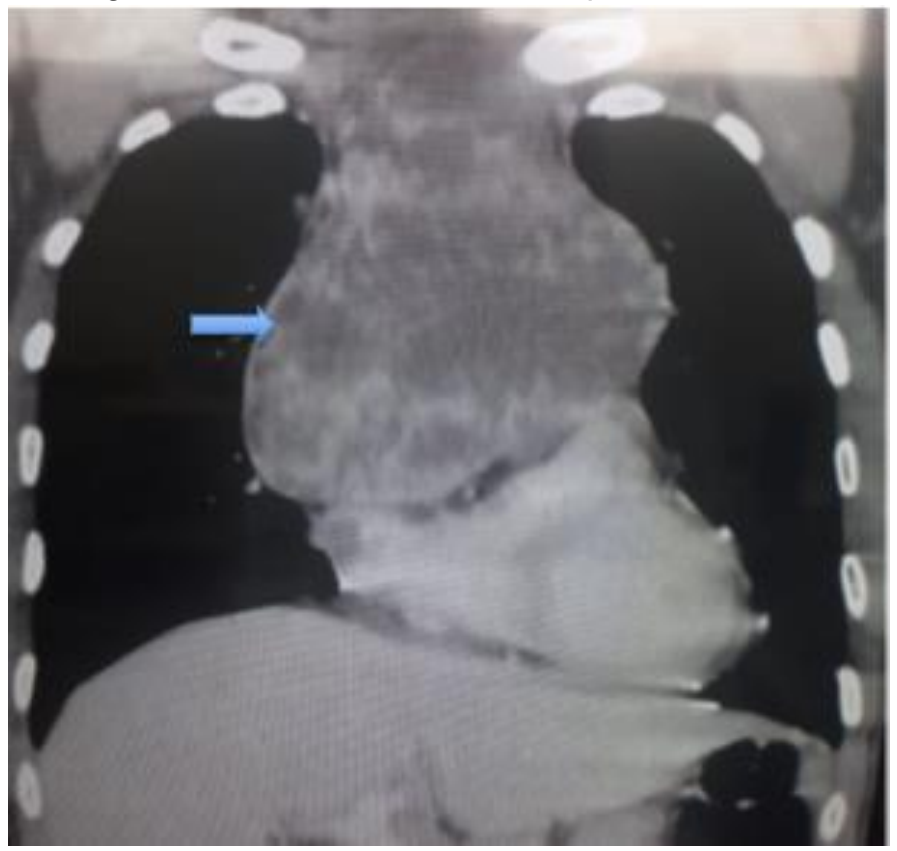

Fonte: Peixoto BFO, et al., 2020.

Paciente negava disfagia, porém iniciou com queixas de dispneia aos pequenos esforços, com piora quando em decúbito dorsal. Apresentava todas as sorologias negativas. Aventado a princípio hipóteses diagnósticas relativas às massas mediastinais anteriores mais comuns, como Linfoma, Teratoma e Timoma. 
No entanto, observou-se massa de crescimento exponencial nos exames de imagem, com intervalo de um mês da primeira radiografia, mantendo característica de borda irregular (Figura 3).

Figura 2 - Rx de tórax PA e PERFIL demonstrando aumento da massa mediastinal com bordas irregulares e aspecto grosseiro de crescimento, conforme demonstrado nas setas.
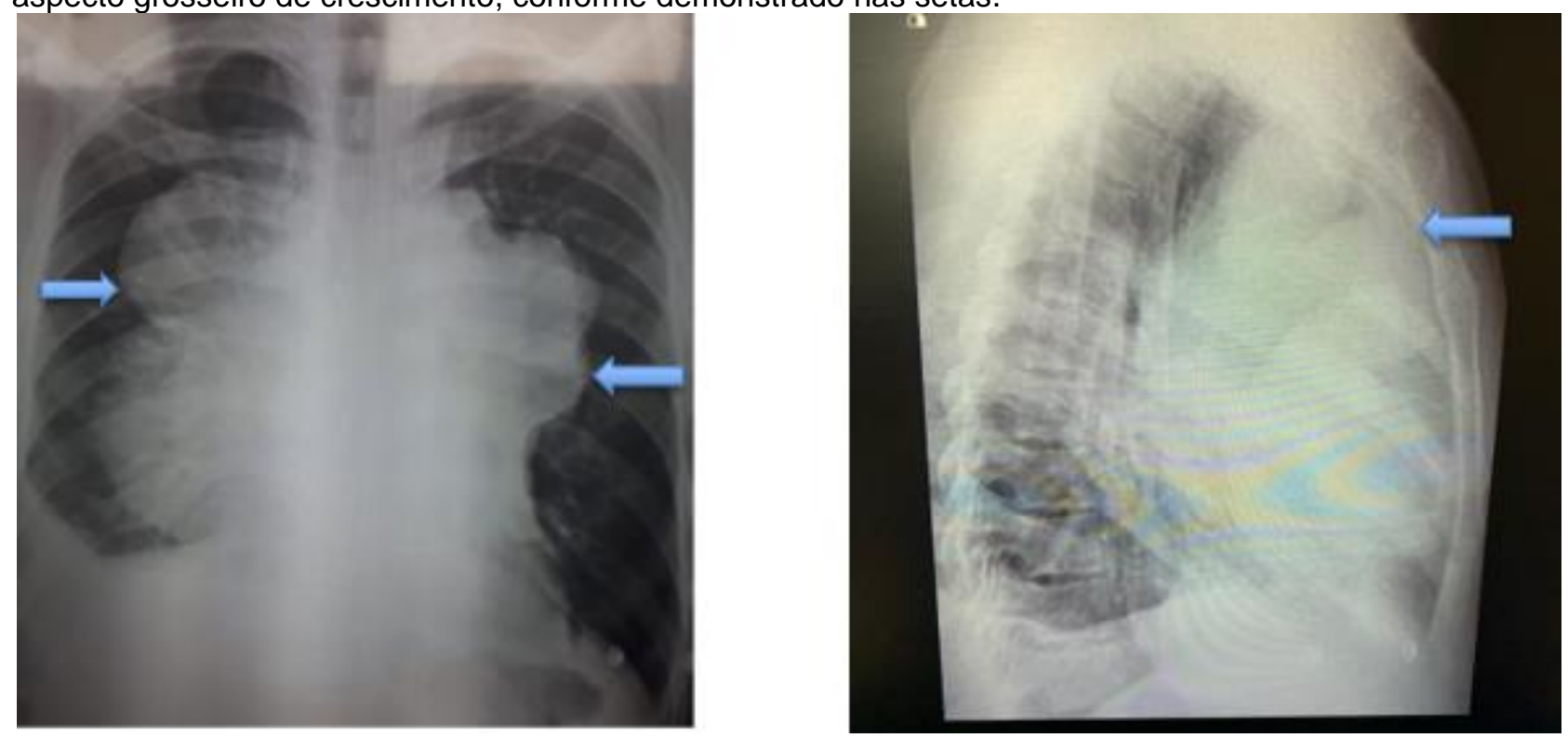

Fonte: Peixoto BFO, et al., 2020.

Com auxílio da cirurgia torácica foi realizado a princípio biópsia por técnica de toracotomia mínima de Chamberlain do local da massa. No entanto, o primeiro achado de anatomopatológico apresentou resultado inconclusivo. Optou-se neste momento, por programação de nova reabordagem para biópsia.

Então, foi submetido em Centro cirúrgico à Esternotomia, com realização de nova biópsia, não sendo possível a exérese da massa mediastinal anterior pelo tamanho e infiltração local. Após o procedimento, ficou em cuidados intensivos e evoluiu com necessidade de ventilação mecânica.

Resultado da biópsia demonstrou se tratar de neoplasia de células germinativas não seminomatosa, do tipo de seio endodérmico, conhecido como "Yolk Sac Tumor" ou "Tumor do Saco Vitelínico", justificando tumor de crescimento rápido e aspecto grosseiro.

Apresentou alfafetoproteína ácida sérica positiva 24.563 (Valor de referência < 8), com beta-HCG de 5 , valor considerado positivo em homens. Em sua imunohistoquímica apresentou positividade para Alfafetoproteína e Cytokeratin Cocktail, reiterando quadro sugestivo de Tumor do Saco Vitelínico (Tabela 1, Figura 4).

Tabela 1 - Painel de imunohistoquímica - demonstrando positividade para Alfafetoproteína.

\section{Painel de Anticorpos}

Cytokeratin Coktail (CellMarque, clone AE1/AE3)

Placental Alkaline Phosphatase (Dako, clone 8 A 9)

\section{Alfha - 1-fetoprotein (Dako, polyclonal)}

CD 30 (Dako, clone Ber-H2)

Octamer-binding transcription factor $3 / 4$ (Dako, clone NINK)

Thyroid transcrition factor-1 (Dako, clone 8G7G3/1)

CD 45 (CellMarque, clone 2B11 \& PD7/26)
Resultado

\section{Positivo}

Negativo

\section{Positivo}

Negativo

Negativo

Negativo

Negativo

Fonte: Peixoto BFO, et al., 2020. 
Figura 3 - Lâmina de imunohistoquímica do paciente do estudo positiva para alfafetoproteína.

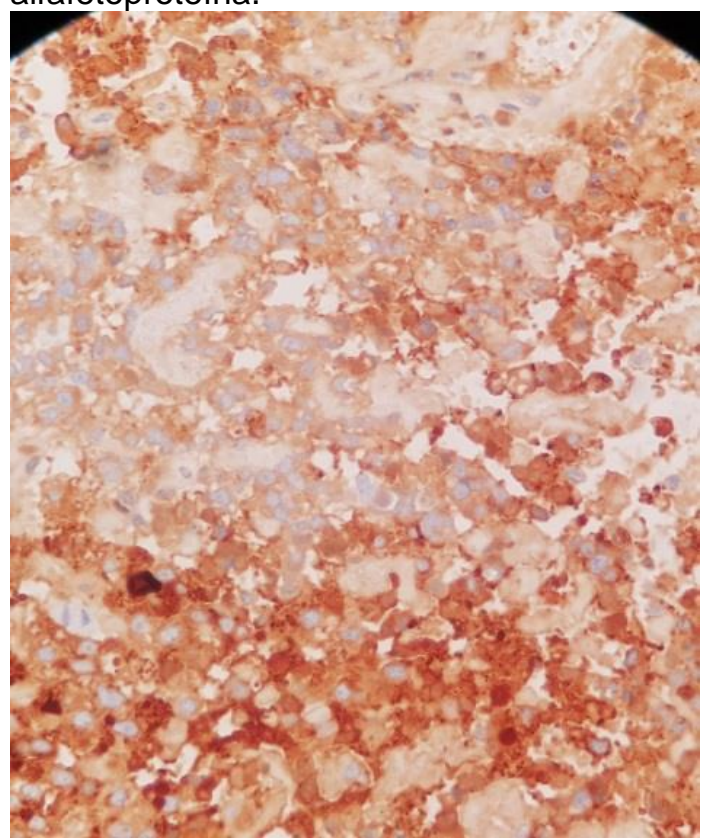

Fonte: Peixoto BFO, et al., 2020.

Contatado equipe da Oncologia Clínica, sendo iniciado de imediato quimioterapia com Etoposídeo, Ifosfamida e Cisplatina. Após primeira sessão de quimioterapia, estando o paciente ainda em ventilação mecânica em leito de cuidados intensivos, evoluiu para óbito com quatro meses de evolução da doença.

\section{DISCUSSÃO}

Quando abordamos patologias localizadas no mediastino anterior há uma tendência a direcionar o raciocínio às doenças tumorais mais comuns localizadas nesta região, tais como, linfomas, timomas e teratomas. No entanto, cabe ressaltar a relevância dos tumores de células germinativas ali localizados por sua rara aparição e curso clínico reservado.

Primeiramente, o mediastino em si é subdivido em porção anterior, média e posterior. O mediastino anterior é limitado anteriormente pelo esterno e posteriormente pelo folheto anterior do pericárdio, é a localização mediastinal com maior incidência de massas tumorais, com predominância aos tumores de derivação tímica (FERNANDEZ A, 2015).

Os tumores de células germinativas são lesões tumorais variadas que apresentam padrões histológicos distintos. Podem ser classificados em teratomas, seminomas, não seminomas e padrão histológico combinado. Cada vertente cursa com uma apresentação clínica, prognóstico e tratamento diferentes (COUTO WJ, et al., 2006).

Os tumores não seminomatosos, representam de 1 a 3,5\% de todos os tumores mediastinais, nele se enquadra o Tumor do Saco Vitelínico ou em inglês tido como "Yolk Sac Tumor", é um dos tumores mais raros encontrados e foi inicialmente descrito em 1967. Há ainda nesta categoria, os carcinomas embrionários, coriocarcinomas e tumores de células germinativas não teratomatosos combinados (NAKHLA SG e SUNDARARAJAN S, 2016).

O tumor do saco vitelínico tem associação direta com níveis altos de alfafetoproteína, diferente de outros tumores de células germinativas não seminomatosos. Tal marcador tumoral tem correlação com o tipo histológico, apesar de não ser patognomônico, e relação com a resposta terapêutica. Valores maiores que 10.000 demonstram piores prognósticos. Marcadores tumorais, como alfafetoprotéina e beta-HCG são importantes na avaliação primária de qualquer tumor mediastinal anterior (COUTO WJ, et al., 2006; NAKHLA SG e SUNDARARAJAN S, 2016). O paciente do estudo apresentou valor de alfafetoprotéina de 24.563, reiterando a possibilidade diagnóstica de tumor do saco vitelínico. 
O tumor do saco vitelínico acomete principalmente o sexo masculino e em idade mais jovem (entre 15 e 35 anos), inúmeros estudos evidenciaram a ligação desse tipo de tumor com alterações também hematológicas decorrente da alteração cromossômica denominada i(12)(p10) e a Síndrome de Klinefelter (COUTO WJ, et al., 2006; MEDEIRO CR, 2000).

As sintomatologias dos tumores de localização de mediastino anterior dependem do padrão de crescimento e infiltração local. Podem ocorrer pacientes oligossintomáticos, a pacientes com sintomas à distância por síndrome paraneoplásica. No caso do tumor do saco vitelínico, como o mesmo cursa com crescimento rápido e infiltração local, é comum os pacientes com a evolução da doença apresentarem sintomas de compressão local, como dispneia, disfagia e consequentemente, insuficiência respiratória.

Um estudo internacional com 341 pacientes com tumor de células germinativas mediastinal cita os sintomas mais comuns na apresentação inicial, como sendo: dispneia (25\%), dor torácica (23\%), tosse (17\%), febre $(13 \%)$, perda de peso $(11 \%)$, síndrome de oclusão de veia cava $(6 \%)$, fraqueza ou cansaço $(6 \%)$ e dor em outras localizações além do tórax $(5 \%)$.

No caso relatado, o paciente iniciou com sintomas inespecíficos, sendo diversas vezes liberado nos primeiros atendimentos, com a progressão da doença os sintomas decorrentes da compressão local se tornaram mais evidentes, culminando ao final em necessidade de ventilação mecânica devido ao quadro de insuficiência respiratória (BOKEMEYER C, et al., 2002).

Inicialmente, acreditava-se que todos os tumores germinativos extragonadais eram derivados de tumores germinativos primários gonadais (testiculares, por exemplo) ainda obscuros. No entanto, atualmente acreditasse que as células germinativas durante a migração da crista urogenital na embriogênese se localizaram em alguns pontos anatômicos, como é o caso do mediastino anterior, glândula pineal e região sacrococcígea. Raramente são encontrados em estômago, vagina, próstata e órbita (MEDEIRO CR, 2000).

Devido ao rápido crescimento a condução dos pacientes com tumores não seminomatosos, em particular o tumor do saco vitelínico, muitas vezes se torna frustrada. O crescimento evidenciado através de exames de imagem, como a tomografia de tórax, demonstra padrão de massa com bordas irregulares, aspecto mais agressivo e grosseiro, borrando os planos entre vasos, e quando contrastada, é possível ver pontos de padrão heterogêneo, compatível com áreas de necrose.

Alguns trabalhos correlacionam o padrão de crescimento acelerado, se tornando grandes massas mediastinais anteriores, associada à valores altos de alfafetoproteína, e muitas vezes beta-hcg, com o diagnóstico de tumor do saco vitelínico, porém não afastam a necessidade de biópsia para estudo anatomopatológico e, posterioremente, imunohistoquímico (FERNANDEZ A, 2015).

Para a realização da biópsia, a mediastinotomia anterior, ou procedimento de Chamberlain, pode ser realizado para acesso da lesão. Contudo, no paciente do estudo não conseguimos através dela uma boa amostra que pudesse ser interpretada. Outras abordagens mais invasivas podem ser realizadas, como esternotomia com biópsia direta lesão.

O estudo histológico do tumor do saco vitelínico apresenta um padrão tubulopapilar com os corpos de Schiller-Duval, e quando corado na imunohistoquímica nota-se positividade para alfafetoproteína ácida (KALHOR N e MORAN CA, 2018). O tratamento e sua efetividade baseiam no rápido diagnóstico anatomopatológico e imunohistoquímico com o início imediato de quimioterapia. A quimioterapia deverá estar associada à cisplatina, e quando possível realização cirúrgica para ressecção da massa tumoral (tanto com intuito citoredutor, quanto para ressecar massas residuais).

Devido ao comportamento agressivo o prognóstico é bastante adverso, em sua maioria na oportunidade do diagnóstico a massa já está irressecável. No paciente do estudo, foram utilizados como quimioterápicos Cisplatina, Etoposídeo e Ifosfamida, a ressecção cirúrgica se tornou inviável devido infiltração local. $\mathrm{Na}$ Classificação do Consenso Internacional dos Tumores de Células Germinativas, os pacientes com tumores não seminomatosos de localização primária do mediastino representam um conjunto de doenças com fator prognóstico adverso, pois a sobrevida em cinco anos encontra-se ao redor de 40\% (COUTO WJ, et al., 2006). 
Cabe ressaltar, quando na vigência de jovens do sexo masculino com massas tumorais anteriores de crescimento acelerado, incluir no campo etiológico tumores derivados de células germinativas é algo de grande valia na condução clínica. Uma vez que, o correto diagnóstico poderá ser feito com antecedência e o tratamento instituído. Desta maneira, poderemos reduzir o desfecho desfavorável da doença em alguns casos. KALHOR N e MORAN CA, 2018).

Por fim, os tumores mediastinais anteriores apresentam inúmeras etiologias histológicas. Os tumores derivados de células germinativas extragonadais englobam entidades raras quando em localização mediastinal, dentre eles, o tumor do seio endodérmico não seminomatoso do tipo do saco vitelínico, o qual apresenta acelerado crescimento, alta capacidade de infiltração local e prognóstico ruim. Dada a elevada mortalidade e reduzida taxa de sobrevida nestes pacientes é de suma importância ampliar o conhecimento médico sobre a patologia visando diagnóstico e instituição terapêutica precoces.

\section{REFERÊNCIAS}

1. AKASBI Y, et al. Complete histologic response to chemotherapy in a patient with a mediastinal yolk sac tumor: a case report. BMC Research Notes 2014, 7:803.

2. BOKEMEYER C, et al. Extragonadal germ cell tumors of the mediastinum and retroperitoneum: results from an international analysis". Journal of Clinical Oncology, 2002; 20(7), 1864-1873.

3. CAPELOZZI VL. Conceitos em patologia do mediastino. Uma correlação anátomo-radiológica. J Pneumol 24(6). novdez de 1998.

4. COUTO WJ, et al. Tumores de células germinativas primárias do mediastino. Rev Assoc Med Bras 2006; 52(3): 1826.

5. FERNANDEZ A. Tumores de mediastino anterior. Sociedade Brasileira de Cirurgia Torácica, 2015.

6. JUDICE LF, et al. Tumores do mediastino. Colégio brasileiro de cirurgiões, 2010. pp. 31-44.

7. KALHOR N, MORAN CA. Primary germ cell tumors of the mediastinum: a review, 2018; 2(1).

8. KESLER KA, et al. Primary mediastinal nonseminomatous germ cell tumors: the influence of postchemotherapy pathology on long-termm survival after surgery. The Journal of Thoracic and Cardiovascular Surgery October 1999.

9. MACCHIARINI P, OSTERTA H. Uncommon primary mediastinal tumours. Lancet Oncol, 2004;5(2):107-18.

10. MEDEIROS C.R. Tumor mediastinal de células germinativas e sua relação com anormalidades hematológicas. Rev.bras.hematol.hemoter., 2000; 22(2): 129-132.

11. MONTEIRO R, et al. Massas mediastínicas - Análise de uma casuística. Acta Med Port. 2011; 24(6):899-904.

12. MORAN CA, et al. Primary germ cell tumor of the mediastinum: III. Yolk sac tumor, embryonal carcinoma, choriocarcinoma and combined nonteratomatous germs cell tumor of the mediastinum- a clinicapathologic and imunnnohistochemical study of 64 cases. 1997;80(4):699-707.

13. NAKHLA SG, SUNDARARAJAN S. A rare case of primary anterior mediastinal yolk sac tumor in an elderly adult male. Case Rep Oncol Med. 2016.

14. NICHOLS CR. Mediastinal germ cell tumors. Semin Thorac Cardiovasc Surg. 1992;4(1):45-50.

15. SILVIA LLC, et al. Tumor de saco vitelínico primário do mediastino: raro caso em um adulto jovem. Einstein. 2017;15(4):496-9.

16. TEILMANN I, et al. Primary germ cell tumor of the anterior mediastinum with features of endodermal sinus tumor. (Mesoblastoma vitellinum). Acta Pathol Microbiol Scand. 1967;70(2):267-78.

17. TINICA G, et al. A mediastinal germ cell tumor of yolk sac type - case report. Chirurgia, 2010; 105(6): 831-834. 